\title{
Religious and Cultural Aspects of Hand Hygiene in Healthcare Accreditations: A Review of Literature
}

\author{
Zuber Mujeeb Shaikh \\ Director of Corporate Quality Improvement, \\ Dr. Sulaiman Al Habib Medical Services Group Company, \\ Riyadh-11643, Kingdom of Saudi Arabia \\ Email : drzuber5@yahoo.co.in
}

Area/Section: Health Sciences.

Type of the Paper: Review.

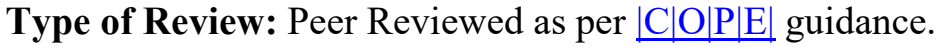

Indexed in: OpenAIRE.

DOI: http://doi.org/10.5281/zenodo.3773876.

Google Scholar Citation: IJHSP

\section{How to Cite this Paper:}

Shaikh, Zuber Mujeeb. (2020). Religious and Cultural Aspects of Hand Hygiene in Healthcare Accreditations: A Review of Literature. International Journal of Health Sciences and Pharmacy (IJHSP), 4(1), 40-48. DOI: http://doi.org/10.5281/zenodo.3773876.

International Journal of Health Sciences and Pharmacy (IJHSP)

A Refereed International Journal of Srinivas University, India.

(C) With Author.

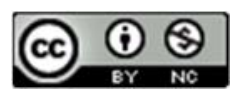

This work is licensed under a Creative Commons Attribution Non-Commercial 4.0 International License subject to proper citation to the publication source of the work.

Disclaimer: The scholarly papers as reviewed and published by the Srinivas Publications (S.P.), India are the views and opinions of their respective authors and are not the views or opinions of the SP. The SP disclaims of any harm or loss caused due to the published content to any party. 


\title{
Religious and Cultural Aspects of Hand Hygiene in Healthcare Accreditations: A Review of Literature
}

\author{
Zuber Mujeeb Shaikh \\ Director of Corporate Quality Improvement, \\ Dr. Sulaiman Al Habib Medical Services Group Company, \\ Riyadh-11643, Kingdom of Saudi Arabia \\ Email: drzuber5@yahoo.co.in
}

\begin{abstract}
Practice of hand hygiene is a very ancient concept of personal cleanliness which reflects in several religious and practiced in numerous cultures. It is worth to consider the grounds of religious and cultural issues in promoting hand hygiene in healthcare services in order to be more effective. Objectives: To study the review of literature of religious and cultural aspects of hand hygiene in healthcare accreditations. Methods: It is a descriptive study in which the several literatures on religious and cultural aspects of hand hygiene in healthcare accreditations were studied. Significance of Research: Healthcare Associated Infections (HCAI) are major threat to patient safety which increases the length of stay, long-term disability, increased resistance of microorganisms to antimicrobials, massive additional financial burden, high costs for patients and their families, and excess deaths. Data Collections: The data was collected from relevant published journals, articles, research papers, academic literature and web portals. Conclusion: Community behaviour influences health care worker's professional behaviour has been supported by insufficient scientific facts until now. There are no data existing on the impact of religious customs on hand hygiene observance in health-care settings where religion is very deep-seated.
\end{abstract}

Keywords: Hand hygiene, Healthcare, Beliefs, Cultures, Religion, Accreditation.

\section{INTRODUCTION :}

Hand hygiene is not a new concept, as it was discussed and elaborated years ago in several religions and their respective religious books. Hence, while planning to promote hand hygiene in healthcare services the numerous grounds of religious and cultural issues should be considered in order to be more effective. Hence, the different cultural and religious beliefs should strongly influence the implementation of hand hygiene practices. The researchers have proved that among the most widely represented number of religious faiths worldwide, there is a potential influence of transcultural and religious factors on attitudes towards hand hygiene practices among healthcare workers [1].

Although water is customarily called a "universal solvent", it should not be used alone to wash the hands as soap or detergent must be applied along with water to remove the hydrophobic materials frequently exists on grubby hands. A simple and very effective way to prevent infections is to be committed in practicing hand hygiene. It averts and extends of microorganisms which are resistant to antibiotics and are becoming difficult to treat. The compliance to hand hygiene on an average in healthcare services is less than half of the times they should.

Belief and medicine have for all time been incorporated into the therapeutic procedure as many priests, monks, theologians and others inspired by religious inspirations premeditated, investigated, and experienced medicine. In general, religious faith has time and again symbolized an exceptional importance to the ethical insinuations of health care and to pay attention on both the physical and spiritual natures of human beings.

Hand hygiene is still meticulously unexplored area and has an intricate connection between religion, culture, and health. In the increasingly multicultural, globalized society and diverse 
populations, a cultural awareness has never been more crucial for implementing good clinical practice and the diverse cultural beliefs are also more prevalent than ever.

The healthcare personnel's conformity with hand hygiene depends on their orientation to a community oriented not to an individualoriented society. As a part of religious belief, in the Hindu culture, hands are rubbed vigorously with ash or mud and then rinsed with water. The research studies conducted in Bangladesh have confirmed that the hand cleansing with mud and ash is as efficient as with soap [2].

Use of alcohol-based hand rubs; alcohol, hand gestures and explanation of "visibly dirty hands" concepts are prohibited for hand hygiene practices in some religions, cultures and beliefs.

\section{DIFFERENT BELIEFS AND HAND HYGIENE :}

Individual cleanliness is a key constituent of personal health not considering of faith, customs or place of origin. Factors such as an environment, education, and culture affect the behaviour of human towards their health. Moreover, in the first 10 years of life only the hand sanitization habits are established [3], which subsequently affects the approach to hand sanitization throughout life, which is called "inherent hand hygiene" [4], which rivals the acknowledged request to eliminate grime from the skin.

During health-care delivery, the healthcare workers may wash their hands and such attitude of hand washing is called "elective hand washing practice" [5]. It has been noticed that in some populations, equally essential and elective hand hygiene practices are extremely prejudiced by cultural and religious factors.

Hand cleanliness is experienced for sanitation, ceremonies, during religious rituals, and figurative motives. In Judaism, Islam and Sikhism they have specific regulations for hand washing as specified in the holy books. The hand washing practice intersperse numerous decisive instants of the day and day today activities. It has been observed that individuals who are very keen on hand hygiene in their personal lives are also very keen in their professional lives as well.

In the Sikh philosophy, hand cleanliness is not only a holy act, but a vital component of daily life. Sikhs will constantly wash their hands appropriately by soap and water afore bandage a wound. This behaviour is obviously expected to be adopted by health care workers during patient care [6].

The Islam religion is based on five pillars, one of which is observing regular prayer five times daily. Individual hygiene is supreme to worship in Islam [7] and before praying, Muslims must perform systematic ablutions as per the holy Quran [8]in running water. Thus, every attentive Muslim is required to maintain conscientious individual hygiene at five times a day, apart from his/her usual routine of bathing. The significance of accurate ablution habits goes beyond Muslims of all races, cultures and ages [9]. Muslims should wash their hands regularly and particularly following a few clearly defined tasks as urged by the Prophet Mohammed [10].

Concerning hand hygiene behaviour, ritual sprinkling of holy water on hands before the consecration of bread and wine, and of the washing of hands after touching the holy oil (the latter only in the Catholic Church) are exempted in the Christian belief. The individual cleanliness and body care are not imperative in the Christian way of life.

There is no specific implication about hand hygiene in daily life and during ritual junctures, apart from the hygienic act of washing hands after each meal in the Buddhist belief. Drizzling water on the hands of the deceased before burning/ burial determines mercy to each other. A gesture of a young person to pour some water on the hands of elders indicates good health and a long life on the occasion of the New Year in Buddhist belief about hand hygiene.

It is habitual to offer amenities for hand aspersion (a bowl of water with special leaves) outside the house door to greet guests and to permit them to wash their face and hands prior to even enquiring the reason of their visit in some African countries like Ghana and some other West African countries.

\section{HAND GESTURES IN DIVERSEFAITHS AND CUSTOMS :}

Use of explicit hand gestures acquire on substantial implication in a certain society [11]. The most general accepted faith about hands, for instance in Hindu, Islam, and some African cultures, is to believe the left hand as "unclean" 
and to be used exclusively for "hygienic" reasons, while it is considered ethnically vital to use the right hand for presenting, accepting, consuming, for spotting at something or when gesticulating.

A precise enriching connotation is specified to the custom of folding hands together whichever as a form of greeting, as well as in prayer in the Sikh and Hindu traditions. In Mahayana and Tibetan Buddhism, there are many hand gestures. Also, in Theravada Buddhist nations, positioning two hands together shaped like a lotus flower is representative of the flower presented to pay esteem to the Buddha, Dhamma (teaching) and Sangha (monk). Moreover, cleaning hands in a clockwise movement is suggested and goes well with the positive way of joyful and propitious instances. Recent researches have revealed the significance of the role of gesture in education and training and have a potential advantage to consider for the educating hand hygiene, in meticulous, its demonstration in illustrative descriptions for diverse traditions [12].

\section{VISIBLY DIRTY HANDS :}

The Centers for Disease Control and Prevention (CDC) and World Health Organization (WHO) guidelines [13] advocate that healthcare workers clean their hands with soap and water when evidently dirty. If not, hand rubbing with an alcohol based rub is optional for all other occasions for hand hygiene while patient care as it is quicker, more efficient, and better endured by the skin. Infection control practitioners find it hard to describe accurately the connotation of "visibly dirty" and to give realistic illustrations while teaching healthcare workers in hand hygiene practices.

As per some beliefs, the theory of dirt is not sternly visual, but imitates a broad importance which refers to interior and exterior cleanliness [14]. External and internal cleanliness is consistently listed as a fundamental good value in the holy books of Hindu religion such as Bhagavadgita, Yoga Shastra of Patanjali.

In addition, in the Jewish belief, the custom of cleaning hands right away after getting-up in the morning refers to the reality that throughout the night, which is measured one sixtieth of death, hands may have touched a dirty area and as a result entails that dirt can be imperceptible to the bare eye.

\section{ALCOHOL AND ALCOHOL-BASED HAND RUBS :}

According to systematic facts alcohol-based hand rubs are measured the gold standard approach and hence, the World Health Organization advocate the use of alcohol-based formulations worldwide. In a number of faiths, alcohol use is forbidden or considered a crime necessitating a self-punishment (Sikhism) since it is measured as a reason for mental destruction (Hinduism, Islam). However, in the Shantiparvan Hindu textbook it is clearly stated that it is not sinful to drink alcohol for therapeutic reasons.

As per the law of kamma, the act or the purpose to execute alive beings is measured an evil act. As microorganisms are lives, carnage them with an alcohol-based hand rub may lead to failing. Thus, when associating a life of a patient and bacterium, maximum persons following to the Buddhist kamma decide that a patient's life is added valued [15].

In Islamic custom consuming or use of alcohol is forbidden and it is considered as haram (forbidden) because it is a substance leading to intoxication and a different state of concentration. Nevertheless, any constituent established to recover disease is allowable in Muslims.

\section{HEALTHCARE ACCREDITATIONS IMPACT ON HEALTHCARE SERVICES:}

The increased international focus on improving patient outcomes, safety and quality of care has led stakeholders, policy makers and health care provider organizations adopt standardized processes for measuring health care systems [16]. The augmented global emphasis on refining patient outcomes, safety and quality of care has led stakeholders, policy makers and health care provider organizations adopt standardized processes for measuring health care systems.

The researchers have proved in recent studies that there is a positive impact of health care accreditation on the health care services. The accreditation has a positive impact on the satisfaction of several Department Services such as Physiotherapy [17], Pharmacy [18], Dietary [19], Laboratory [20], Emergency [21], Out-Patient [22], In-Patient [23], Hemodialysis 
[24], Radiology [25], Ambulance [26], and also has positive impact on the reporting of Occurrence Variance Reports [27], completeness of personnel files in Human Resource Department [28]. A comparative study of laboratory and blood bank performance by using the quality indicators revealed that the mean rating of the second half (after the accreditation) is better than the mean rating of the first half (before accreditation) [29].

The Impact of Hospital Accreditation on the Patients Satisfaction of Haemodialysis Department Services revealed that the participation of patients had increased only after accreditation [30]; there is no significant difference in the Age categories [31]; gender [32]; geographical status [33]; language [34]; type of payment made [35]; there is a significant difference in the satisfaction with respect to courtesy [36]; waiting time [37]; professionalism/friendliness [38]; doctors involved in the patient's care [39]; nurses involved in the patient's care [40]; way staff explained the procedure [41]; level of privacy [42]; cleanliness and safety [43]; amount of time the doctors spent with the patient [44]; amount of time the nurses spent with the patient pain/uncomfortable [45]; process [46]; comfort [47]; effectiveness [48]; overall experience [49] and overall satisfaction [50].

The researchers have also compared the healthcare accreditation standards and revealed that there are variations among the compared standards despite of being accredited by the International Society for Quality in Health Care (ISQua). The critical analysis of Patient and Family Rights (PFR) standards [51], Patient and Family Education (PFE) standards [52] and International Patient Safety Goals (IPSG) standards [53] in the Joint Commission International (JCI) Accreditation and Central Board for Accreditation of Healthcare Institutes (CBAHI) standards for hospitals clearly show that the PFR and PFE standards are very comprehensive than the JCI Accreditation standards whereas the IPSG standards in JCI Accreditation are much comprehensive than CBAHI Standards. The critical analysis of Staff Qualifications and Education (SQE) standards in JCI Accreditation and Medical Staff (MS) \& Staffing Management (SM) standards in Det Norske Veritas (DNV) Accreditation for hospitals clearly shows that the SQE Standards in JCI Accreditation are very comprehensive than the DNV's National Integrated Accreditation for Healthcare Organizations (NIAHO) Accreditation [54].

\section{CONCLUSIONS :}

Community behavior influences health care worker's professional behavior has been supported by insufficient scientific facts until now and there are no data or references exists on the impact of religious customs on hand hygiene observance in healthcare settings where religion is very deep-seated.

\section{DIRECTIONS FOR FUTURE RESEARCH}

This is a very fascinating field of research in an international point of view; as such information could be very useful to identify the best components of a programme for hand hygiene promotion and the link between religious and health issues may be very beneficial.

\section{DISCLAIMER :}

This publication contains information obtained from authentic and highly regarded sources. Reasonable effort has been made to publish reliable data and information, but the author and the publisher cannot assume responsibility for the validity of all materials or for the consequences of the use.

\section{REFERENCES :}

[1] Major religions of the world ranked by number of adherents, http://www.adherents.com/Religions_By_Adh erents.html.

[2] Hoque BA, Briend A. A comparison of local handwashing agents in Bangladesh. Journal of Tropical Medicine and Hygiene, 1991, 94:6164.

[3] Whitby M, McLaws M-L, Ross RW. Why healthcare workers don't wash their hands: a behavioral explanation. Infection Control Hospital Epidemiology, 2006, 27:484-492.

[4] Whitby $\mathrm{M}$ et al. Behavioural considerations for hand hygiene practices: the basic building blocks. Journal of Hospital Infection, 2007, $65: 1-8$.

[5] Whitby M, McLaws M-L, Ross RW. Why healthcare workers don't wash their hands: a behavioral explanation. Infection Control 
Hospital Epidemiology, 2006, 27:484-492.

[6] Whitby M, McLaws M-L, Ross RW. Why healthcare workers don't wash their hands: a behavioral explanation. Infection Control Hospital Epidemiology, 2006, 27:484-492.

[7] Lawrence P, Rozmus C. Culturally sensitive care of the Muslim patient. Journal of Transcultural Nursing, 2001, 12:228-233.

[8] Muftic D. [Maintaining cleanliness and protecting health as proclaimed by Koran texts and hadiths of Mohammed SAVS, in Croatian] Medicinski Arhiv, 1997, 51:41-43.

[9] Ahmed QA et al. Muslim health-care workers and alcohol based hand rubs. Lancet, 2006, 367:1025-1027.

[10] Katme AM. Hand washing. Muslim teaching gives rules for when hands must be washed. BMJ, 1999, 319:520.

[11] Watts G. You need hands. Lancet, 2006, 367:1383-1384.

[12] Perry M, Berch D, Singleton J. Constructing shared understanding: the role of non-verbal input in learning contexts. Journal of Contemporary Legal Issues, 1995, 6:213235.

[13] Boyce JM, Pittet D. Guideline for hand hygiene in healthcare settings. Recommendations of the Healthcare Infection Control Practices Advisory Committee and the HICPAC/SHEA/APIC/IDSA Hand Hygiene Task Force. Morbidity and Mortality Weekly Report, 2002, 51:1-45.

[14] Henley A, Schott J. Religious beliefs and practices. In: Clarke $\mathrm{G}$, ed. Culture, religion and patient care in a multiethnic society. London, Age Concern, 1999:92-104.

[15] Thepvethee P. et al. Abortion, how should we decide? Bangkok, Buddha-Dhamma Foundation, 1993.

[16] Brubakk et al. A systematic review of hospital accreditation: the challenges of measuring complex intervention effects, BMC Health Services Research (2015) 15:280.

[17] Shaikh, Zuber. (2017). The Impact of Hospital Accreditation on the Patient's Satisfaction of Physiotherapy Department Services. International Journal of Business, Management and Allied Sciences (IJBMAS),
4(4.2017),

143-154. http://doi.org/10.13140/RG.2.2.33967.64161.

[18] Shaikh, Zuber. (2017). The Impact of Hospital Accreditation on the Patient's Satisfaction of Pharmacy Department Services. International Journal of Business, Management and Allied Sciences, 4(4.2017), 189-199. http://doi.org/10.13140/RG.2.2.35499.54566.

[19] Shaikh, Zuber. (2017). The Impact of Hospital Accreditation on the Patients Satisfaction of Dietary Services. International Journal of Business, Management and Allied Sciences (IJBMAS), 4(4.2017), 1-12. http://doi.org/10.13140/RG.2.2.23409.79200.

[20] Shaikh, Zuber. (2017). The Impact of Hospital Accreditation on the Patients Satisfaction of Laboratory Department Services. International Journal of Business, Management and Allied Sciences (IJBMAS), 4(2.2017), 4277- 4289 . http://doi.org/10.13140/RG.2.2.10479.53926.

[21] Shaikh, Zuber. (2017). The Impact of Hospital Accreditation on the Patients Satisfaction of Emergency Department Services. International Journal of Business, Management and Allied Sciences (IJBMAS), 4(3.2017), 4330-4339. http://doi.org/10.13140/RG.2.2.13834.98244.

[22] Shaikh, Zuber. (2017). The Impact of Hospital Accreditation on the Patients Satisfaction of Out-Patient Department Services. International Journal of Business, Management and Allied Sciences (IJBMAS), 4(3.2017), 4384-4398. http://doi.org/10.13140/RG.2.2.17190.42561.

[23] Shaikh, Zuber. (2017). The Impact of Hospital Accreditation on the Patient Satisfaction of In-Patient Department Services. International Journal of Emerging Research in Management \& Technology (IJERMT), 6(8), 368-383.

http://doi.org/10.13140/RG.2.2.19299.04642.

[24] Shaikh, Zuber. (2017). The Impact of Hospital Accreditation on the Patients Satisfaction of Haemodialysis Department Services. International Journal of Emerging Research in Management \& Technology (IJERMT), 6(8), 384-392. http://doi.org/10.13140/RG.2.2.14818.02246. 
[25] Shaikh, Zuber. (2017). The Impact of Hospital Accreditation on the Patients Satisfaction of Radiology Department Services. International Journal of Business, Management and Allied Sciences (IJBMAS), 4(1.2017), 4120-4130.

http://doi.org/10.13140/RG.2.2.26784.89606.

[26] Shaikh, Zuber. (2016). The Impact of Hospital Accreditation on the Ambulance Services Satisfaction. International Journal of Emerging Research In Management \&Technology (IJERMT), 5(12), 76-84. http://doi.org/10.13140/RG.2.2.22367.76968.

[27] Shaikh, Zuber. (2018). The Impact of Hospital Accreditation on the Number of Occurrence Variance Report or Incident Reports. International Journal of Business, Management and Allied Sciences (IJBMAS), 5(1.2018), 15-19. http://doi.org/10.13140/RG.2.2.27256.75525.

[28] Shaikh, Zuber. (2017). The Impact of Hospital Accreditation on the Completeness of Personnel Files in Human Resource Department. International Journal of Business, Management and Allied Sciences (IJBMAS), 4(4.2017), 236-244. http://doi.org/10.13140/RG.2.2.18868.14721.

[29] Shaikh, Zuber. (2018). A Comparative Study on Laboratory and Blood Bank Performance by Using the Quality Indicators. International Journal of Business, Management and Allied Sciences (IJBMAS), 5(1.2018), 1-8. http://doi.org/10.13140/RG.2.2.12850.30403.

[30] Shaikh, Zuber. (2017). The Impact of Hospital Accreditation on the Patients Satisfaction of Haemodialysis Department Services. International Journal of Emerging Research in Management \& Technology (IJERMT), 6(8), 384-392. http://doi.org/10.13140/RG.2.2.14818.02246.

[31] Shaikh, Zuber. (2017). The Impact of Hospital Accreditation on the Patients Satisfaction of Haemodialysis Department Services. International Journal of Emerging Research in Management \& Technology (IJERMT), 6(8), 384-392. http://doi.org/10.13140/RG.2.2.14818.02246.

[32] Shaikh, Zuber. (2017). The Impact of Hospital Accreditation on the Patients Satisfaction of Haemodialysis Department
Services. International Journal of Emerging Research in Management \& Technology (IJERMT), 6(8), 384-392. http://doi.org/10.13140/RG.2.2.14818.02246.

[33] Shaikh, Zuber. (2017). The Impact of Hospital Accreditation on the Patients Satisfaction of Haemodialysis Department Services. International Journal of Emerging Research in Management \& Technology (IJERMT), 6(8), 384-392. http://doi.org/10.13140/RG.2.2.14818.02246.

[34] Shaikh, Zuber. (2017). The Impact of Hospital Accreditation on the Patients Satisfaction of Haemodialysis Department Services. International Journal of Emerging Research in Management \& Technology (IJERMT), 6(8), 384-392. http://doi.org/10.13140/RG.2.2.14818.02246.

[35] Shaikh, Zuber. (2017). The Impact of Hospital Accreditation on the Patients Satisfaction of Haemodialysis Department Services. International Journal of Emerging Research in Management \& Technology (IJERMT), 6(8), 384-392. http://doi.org/10.13140/RG.2.2.14818.02246.

[36] Shaikh, Zuber. (2017). The Impact of Hospital Accreditation on the Patients Satisfaction of Haemodialysis Department Services. International Journal of Emerging Research in Management \& Technology (IJERMT), 6(8), 384-392. http://doi.org/10.13140/RG.2.2.14818.02246.

[37] Shaikh, Zuber. (2017). The Impact of Hospital Accreditation on the Patients Satisfaction of Haemodialysis Department Services. International Journal of Emerging Research in Management \& Technology (IJERMT), 6(8), 384-392. http://doi.org/10.13140/RG.2.2.14818.02246.

[38] Shaikh, Zuber. (2017). The Impact of Hospital Accreditation on the Patients Satisfaction of Haemodialysis Department Services. International Journal of Emerging Research in Management \& Technology (IJERMT), 6(8), 384-392. http://doi.org/10.13140/RG.2.2.14818.02246.

[39] Shaikh, Zuber. (2017). The Impact of Hospital Accreditation on the Patients Satisfaction of Haemodialysis Department Services. International Journal of Emerging 
Research in Management \& Technology (IJERMT), $\quad$ 6(8), 384-392. http://doi.org/10.13140/RG.2.2.14818.02246.

[40] Shaikh, Zuber. (2017). The Impact of Hospital Accreditation on the Patients Satisfaction of Haemodialysis Department Services. International Journal of Emerging Research in Management \& Technology (IJERMT), 6(8), 384-392. http://doi.org/10.13140/RG.2.2.14818.02246.

[41] Shaikh, Zuber. (2017). The Impact of Hospital Accreditation on the Patients Satisfaction of Haemodialysis Department Services. International Journal of Emerging Research in Management \& Technology (IJERMT), 6(8), 384-392. http://doi.org/10.13140/RG.2.2.14818.02246.

[42] Shaikh, Zuber. (2017). The Impact of Hospital Accreditation on the Patients Satisfaction of Haemodialysis Department Services. International Journal of Emerging Research in Management \& Technology (IJERMT), 6(8), 384-392. http://doi.org/10.13140/RG.2.2.14818.02246.

[43] Shaikh, Zuber. (2017). The Impact of Hospital Accreditation on the Patients Satisfaction of Haemodialysis Department Services. International Journal of Emerging Research in Management \& Technology (IJERMT), 6(8), 384-392. http://doi.org/10.13140/RG.2.2.14818.02246.

[44] Shaikh, Zuber. (2017). The Impact of Hospital Accreditation on the Patients Satisfaction of Haemodialysis Department Services. International Journal of Emerging Research in Management \& Technology (IJERMT), 6(8), 384-392. http://doi.org/10.13140/RG.2.2.14818.02246.

[45] Shaikh, Zuber. (2017). The Impact of Hospital Accreditation on the Patients Satisfaction of Haemodialysis Department Services. International Journal of Emerging Research in Management \& Technology (IJERMT), 6(8), 384-392. http://doi.org/10.13140/RG.2.2.14818.02246.

[46] Shaikh, Zuber. (2017). The Impact of Hospital Accreditation on the Patients Satisfaction of Haemodialysis Department Services. International Journal of Emerging Research in Management \& Technology
(IJERMT), 6(8), 384-392. http://doi.org/10.13140/RG.2.2.14818.02246.

[47] Shaikh, Zuber. (2017). The Impact of Hospital Accreditation on the Patients Satisfaction of Haemodialysis Department Services. International Journal of Emerging Research in Management \& Technology (IJERMT), 6(8), 384-392. http://doi.org/10.13140/RG.2.2.14818.02246.

[48] Shaikh, Zuber. (2017). The Impact of Hospital Accreditation on the Patients Satisfaction of Haemodialysis Department Services. International Journal of Emerging Research in Management \& Technology (IJERMT), 6(8), 384-392. http://doi.org/10.13140/RG.2.2.14818.02246.

[49] Shaikh, Zuber. (2017). The Impact of Hospital Accreditation on the Patients Satisfaction of Haemodialysis Department Services. International Journal of Emerging Research in Management \& Technology (IJERMT), 6(8), 384-392. http://doi.org/10.13140/RG.2.2.14818.02246.

[50] Shaikh, Zuber. (2017). The Impact of Hospital Accreditation on the Patients Satisfaction of Haemodialysis Department Services. International Journal of Emerging Research in Management \& Technology (IJERMT), 6(8), 384-392. http://doi.org/10.13140/RG.2.2.14818.02246.

[51] Shaikh, Zuber. (2017). Critical Analysis of Patient and Family Rights in JCI Accreditation and CBAHI Standards for Hospitals. International Journal of Emerging Research in Management \&Technology (IJERMT), 6(7), 324-330.

http://doi.org/10.13140/RG.2.2.15943.60323.

[52] Shaikh, Zuber \& Al-Towyan, S \& Khan, G. (2016). Critical Analysis of Patient and Family Education in JCI Accreditation and CBAHI Standards for Hospitals. International Journal of Research in Business Management (IMPACT: IJRBM), 4(3, Mar 2016), 29-38. http://doi.org/10.13140/RG.2.2.10414.00321.

[53] Shaikh, Zuber \& Al-Towyan, S \& Khan, G. (2016). Critical Analysis of International Patient Safety Goals Standards in JCI Accreditation and CBAHI Standards for Hospitals. International Journal of Research in Business Management (IMPACT: IJRBM), 4(3, 
Mar 2016), 71-78.

http://doi.org/10.13140/RG.2.2.24674.63680.

[54] Shaikh, Zuber \& Al-Towyan, S \& Khan, G. (2016). Critical Analysis of Staff Qualifications and Education Standards in JCI and Medical Staff \& Staffing Management Standards in DNV Accreditation for Hospitals. International Journal of Research in Business Management (IMPACT: IJRBM), 4(3, Mar 2016), 61-70. http://doi.org/10.13140/RG.2.2.17963.75044. 